\section{P-2 COOKERY GROUP FOR BEREAVED ADULTS}

Matt Jackson, Kevin Ratcliffe. St Richard's Hospice, Worcester, UK

10.1136/bmjspcare-2018-hospiceabs.27

For three years St Richard's Hospice has run a successful cookery group for bereaved adults. The group started because it was identified that people struggled with cooking and eating in bereavement. Clients attend six sessions having the opportunity to cook a main course and a dessert under the guidance of the hospice head chef. The group then shared a meal they created together.

It was evident from evaluations following initial groups that isolation, loneliness, loss of confidence and lack of self care are issues for bereaved people. They can lose interest in cooking or not have the confidence or skills to cook for themselves. Cooking and eating with others is a social event. When a loved one dies this opportunity is lost. The aim of the cookery group is to provide a safe place for people to meet other bereaved people to create an environment where trust and friendships develops and to gain pleasure and enjoyment from cooking.

Through cooking and eating together the group found they are able to build trusting relationships with each other and build the confidence to talk about their loss. The challenge and pleasure that is created by learning, preparing and eating beautiful food together gives the clients much needed enjoyment and distractions from other pressures in their lives. They reported that their confidence and enjoyment of cooking grew, their overall diet improved and their social life blossomed as they began to have the confidence to invite family and friends round for dinner. Two of the groups continue to meet and have a 'come dine with me' at each others houses every month.

\section{P-3 EARTHWORKS - BEREAVEMENT ALLOTMENT GROUP FOR MEN}

Jane Cato, Katie Dennis. Martlets Hospice, Brighton and Hove, UK

\subsection{6/bmjspcare-2018-hospiceabs.28}

Aim This innovative project aims to provide a therapeutic space that helps bereaved men meet together with the support of a trained counsellor and volunteer gardener by working and being on an allotment.

Background Following the successful application for funding from Hospice UK, this year-long pilot project uses nature both as a medium of communication and as a source of healing. There is no specific provision in our city or organisation for bereaved men to come together as a group therapeutically or gain peer support. It was identified that out of all individuals supported by the hospice bereavement service over a three year period (2014-2017), just $23 \%$ were men.

The use of allotments to rebuild lives was successfully pioneered by The Natural Growth Project (Linden \& Grut, 2002) run by Freedom from Torture. An Ecotherapy Project successfully delivered support to bereaved people at Springhill Hospice (Maxwell, 2017) and research shows that allotment gardening can improve self-esteem, calm anger and ease depression (Wood, Pretty \& Griffin, 2016).

The Allotment Group is working in partnership with a local community allotment project, PLOT22, and will provide six, 6-weekly groups with eight men in a group, where men can share their stories through working the allotment. Using nature as a metaphor gives clients an opportunity to access deeply held experiences of pain, loss and grief and to work on difficult feelings whilst the life cycle embodied in nature carries the promise of healing. The project is being evaluated using the outcome tool Adult Attitude to Grief (Machin, 2014).

The future There is a commitment to making this project a success and with the integration of user feedback, the aspiration is to continue with the Earthworks Group and introduce new groups for other under-represented groups such as bereaved LGBT people, children and families, pre-bereavement groups for carers and for those individuals living with a terminal illness (Kelly, 2016).

\section{P-4 MAKE, DO AND MEND SUPPORTED BY THE MASONIC CHARITABLE FOUNDATION HOSPICE BEREAVEMENT CARE PROGRAMME}

Lynsey Lawson. St Mary's Hospice, Cumbria, UK

\subsection{6/bmjspcare-2018-hospiceabs.29}

Background As a hospice we recognise that grief is an inevitable part of everyday life, regardless of gender, and can be one of the great isolating forces in life. In line with the Bereavement Care Service Standards (2014) we regularly review our activity to ensure development is in line with emerging needs. Hospice staff noticed that the number of bereaved women who come forward for care and support from us far outnumber men and we wanted to find a new way to reach out to the 'missing men', including bereaved husbands, men caring for their partner and men coming to terms with their own life- shortening illness.

In December 2017 we made a successful application to the Masonic Charitable Foundation Hospice Bereavement Care programme. This application shared our hope to develop a 'Make, Do and Mend 'workshop. Our aim was to reach out to the 'missing men' recognising that one size doesn't fit all.

Aims Our project aims to set up a 'Make, Do and Mend' workshop within our retail warehouse, reaching out to bereaved men and women, those caring for their partner or living with their own life-shortening illness. Workshop participants will work alongside each other on a variety of projects and the essence of the group is not building, but the connections, relationships and support between members. The workshop will be led by an experienced retail manager and bereavement staff, and will take place in a fully equipped DIY workshop environment. The workshops will run throughout the year on Wednesday and Saturday mornings and participants will be invited to attend eight sessions. Through use of the Warwick-Edinburgh Mental Wellbeing Scale (WEMWBS) tool we will seek evidence of an improvement in participants' reported wellbeing at the end of the eight- week programme. 